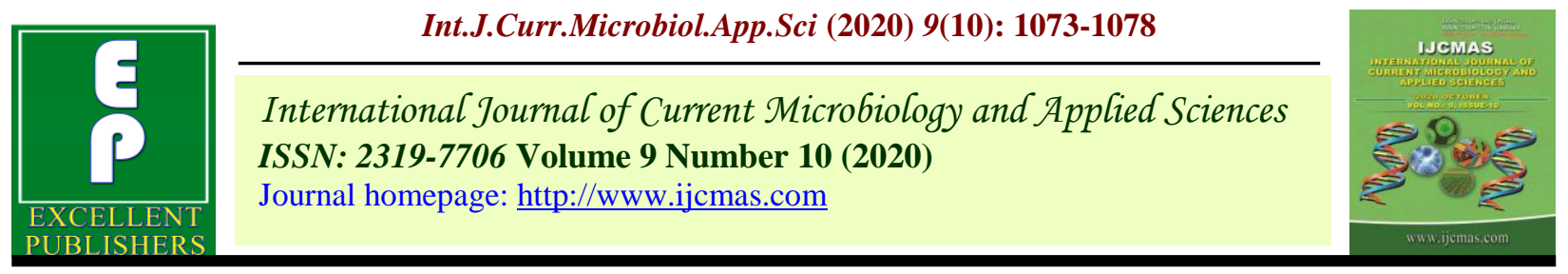

Original Research Article

https://doi.org/10.20546/ijcmas.2020.910.128

\title{
Spatial and Temporal Rainfall Variability of Sub Watershed in Deccan Plateau, India
}

\author{
M. Uma Devi ${ }^{1 *}$, M.D. Reddy $^{2}$, A. Mani ${ }^{3}$, D.V. Mahalakshmi ${ }^{4}$ and O. Bhavani ${ }^{1}$ \\ ${ }^{1}$ Water Technology Centre, Professor Jayashankar Telangana State Agricultural University, \\ Rajendranagar, Hyderabad, India \\ ${ }^{2}$ M.S. Swaminathan School of Agriculture, Centurion University of technology and \\ Management, Parlakhemundi, Odisha - 706211, India \\ ${ }^{3}$ College of Agricultural Engineering, Acharya N.G. Ranga Agricultural University, \\ Bapatla, Andhra Pradesh, India \\ ${ }^{4}$ Land and Atmospheric Physics Division (LAPD), Earth and Climate Sciences Area (ECSA), \\ National Remote Sensing Centre (NRSC), Indian Space Research Organization (ISRO), \\ Hyderabad, 500037, India \\ *Corresponding author
}

\begin{abstract}
A B S T R A C T
The local hydrological, agricultural and economic activities heavily depend on micro-level rainfall. Therefore, this study examines the variability of rain fall in Wargal sub watershed in Siddipet district, Telangana state of India. To study the rainfall variability within the study area of $15 \mathrm{sq} \mathrm{km}, 15$ rain gauges were installed at different locations and data was collected during July and August months, 2009. The rainfall variability map was generated by using GIS software. The weather data was collected by installing the related instruments at Nagarjuna Innovation Centre, Wargal during Sep 2008. It was observed that relatively higher rainfall (310 to $340 \mathrm{~mm}$ ) was received in areas around lower reach (Kothakunta and Bitcherla kunta tanks) and relatively lower rainfall $(250-280 \mathrm{~mm})$ was received in areas around upper reach (Melakunta and Kadelakunta tanks).The areas around middle of watershed (Ausoloni kunta and Ayamgori kunta) received relatively moderate rainfall $(280-310 \mathrm{~mm})$. The rain fall variation was greater in August than July months. During August month most of the rain fed crops of 90-110 days was in reproductive stage and any deficit cause variability yield in the same sub watershed as that observed in Kothakunta sub watershed.
\end{abstract}

\section{Keywords}

Rainfall, Rainfall intensity, Rain gauge, Rainfall variability, Sub watershed

Article Info

Accepted:

10 September 2020

Available Online:

10 October 2020

\section{Introduction}

Agriculture sector in India uses more than $80 \%$ of water. In India, of the total cultivated area only $34.5 \%$ of the area is irrigated contributing $60 \%$ of food grain production. On the other hand, the rain fed area occupies $52 \%$ of cropped area and contributing $40 \%$ of food grain production. This is mainly due to variation in rain fall both time and space. 
The water allocations towards agriculture will decrease as it has to compete with other sectors where returns are more. Hence, it becomes imperative to produce more food with less water, and to higher productivity from rain fed areas. That is, to increase agricultural water productivity particularly rainwater. There is a consensus that climate change has impacted agriculture (FAO, 2007; Mearns and Norton, 2009; Field, 2014 and Solomon et al., 2007) and water is considered as a major means by which climate change affect the Earth's ecosystems. Further, the most important source of water for crop production and animal rearing is rainfall (FAO, 2007; Mearns and Norton, 2009).

In peninsular India, farmers cultivate cereals (maize, bajra, sorghum, finger millets, pulses (redgram, green gram, black gram and cowpea), oil seeds (sunflower, groundnut, til, castor) and vegetables (bhendi, brinjal, beans, potato, ridge guard, onion, bitter guard, and pea), cotton, fruit crops and other commercial crops. Precipitation shows spatio temporal differences at a regional and country level. Further, even in small water shed, the rainfall pattern may be different. Due to variability in rainfall the yield of same crop will be different from one part of village to the other part. This creates difficulty in developing local level recommendations. If the rainfall variability is known, it helps to identify agroecosystem-specific climate change adaptation strategies. Keeping this in view, an effort has been made to analyze the variability of rain fall in Wargal sub watershed in Siddipet district having 482 ha area near Hyderabad in Telangana state of India.

\section{Materials and Methods}

The Wargal village of Wargal mandal (administrative unit containing 18 villages) is located at latitude $17^{0} 41^{\prime} 19.4^{\prime}$ ' $\mathrm{N}$, longitude $78^{0} 29^{\prime} 24.0^{\prime}, \mathrm{E}$, and is $55 \mathrm{~km}$ from
Hyderabad at an elevation of 576-590 m above sea level in Siddipet district of Telangana. The geographical area of Wargal village is 2,618 ha with 2,522 ha cultivable land, of which 1,460 ha is rainfed, 167 ha under tank irrigation and 235 ha under bore wells. The soils of the village is mostly red chalka (Red sandy/sandy clay loams Alfisols, 2,336 ha) and black cotton soils (Vertisols, 280 ha). The watershed area (about $15 \mathrm{sq} \mathrm{km}$ ) selected for the study consists of mostly red soil. The physiography of the area is undulating having a slope of $1-5 \%$, slight erosion, and moderately drained. The depth of the soil is shallow to medium having coarse to medium texture with a $\mathrm{pH}$ range of 6.5 to 7.5. The nitrogen and phosphorus content of the soil is low and potassium content is medium to high. The major amount of rainfall is received during the South-West monsoon and the normal rainfall is $773 \mathrm{~mm}$.

The village is a cluster of 7 hamlets with one big village; there are 23 small to big tanks locally called as kuntas with a command area of 0.4 ha to 18.0 ha. Further, there are three big kuntas with an area of $21.42-27.32$ ha. There are two tanks irrigating 47.2 and 119.04 ha. These small kuntas and tanks are interconnected one and another through drains forming water conservation structures. Further, most of the cultivated as well as waste land is draining into kunta or a tank.

From the 2618 ha of Wargal village, 482 ha sub-watershed under Kothakunta was selected as the study area. In the study area, there are 206 bore wells, the only source irrigating 192.91 ha. The major crops cultivated under bore wells include paddy, maize, vegetables (bhendi, brinjal, beans, potato, ridge guard, onion, bitter guard, and cowpea), cotton and sunflower. To study the rainfall variability within the study area, 15 rain guages were installed at different locations in farmers fields (Fig. 2) and data was collected during 
July and August months, 2009. The rainfall variability map (Fig. 2) was generated using Arc GIS version 9.3 using simple kriging functions under spatial analyst tools.

The weather data was collected by installing the related instruments at Nagarjuna Innovation Centre, Wargal during Sept. 2008 and mean monthly data on maximum and minimum temperatures, evaporation, relative humidity and total rainfall. The rain fall data for the months of January to Sep 2008 were collected from the mandal office, Wargal. The Kothakunta tank was totally filled during kharif 2008 after a gap of nearly ten years. Rainfall distribution in different months during 2008 to 2011 at Kothakunta sub watershed, Wargal, was recorded. Peak rainfall was received during August month in first two years (2008 and 2009), whereas during 2010 and 2011 peak rainfall was recorded in July (Fig. 1).

\section{Results and Discussion}

\section{Rainfall variability}

The total rainfall received was 662.26, 489.03, 1081.5 and $579.2 \mathrm{~mm}$ during 2008, 2009, 2010 and 2011 respectively (Fig. 1). The rainfall data located at different places in the watershed from 15 rain guages for two months during July and August months, 2009 ranged from $270 \mathrm{~mm}$ to $323 \mathrm{~mm}$ with a standard deviation of $+/-21.89 \mathrm{~mm}$. The rainfall variability map (Fig. 2) indicated that rainfall received in July and August months ranged from $250 \mathrm{~mm}$ to $340 \mathrm{~mm}$. The area was divided into three rainfall zones. It was observed that relatively higher rainfall (310 to $340 \mathrm{~mm}$ ) was received in areas around Kothakunta and Bitcherla kunta tanks (lower reach) and relatively lower rainfall (250 - 280 $\mathrm{mm}$ ) was received in areas around Melakunta and Kadelakunta tanks (Upper reach).The areas around Ausoloni kunta and Ayamgori kunta (middle of watershed) received relatively moderate rainfall $(280-310 \mathrm{~mm})$. Kumar et al., (2010) reported a declining trend of annual rainfall over central India and north-east India, and an increase in annual rainfall in other parts of India while analyzing rainfall data for the period 1871-2005.

In July the rainfall ranged from $52.4-64.75$ $\mathrm{mm}$ with S.Ed+/- of 2.98 while in August it varied between 195.55 - $266.45 \mathrm{~mm}$ and a standard deviation of 21.34 (Table 1). It shows that rain fall variation was greater in August than July months. During August month, most of the rain fed crops of 90-110 days was in reproductive stage and any deficit cause variability yield in the same sub watershed as that observed in Kothakunta sub watershed.

Francis Ndamani and Tsunemi Watanab (2015) reported that in the Lawra district of the Upper West Region of Ghana there was moderate seasonal and irregular annual rainfall concentration and the annual rainfall and crop production were negative for all the crops studied. The seasonal rainfall was negatively correlated in case of sorghum, millet and groundnut. Our results indicate that identifying and implementing appropriate adaptation techniques at farm level is essential for obtaining higher production of crops.

In conclusion, the analysis of the rainfall data collected at different places in the watershed from 15 rains during July and August months, 2009 shows that the monsoon season received a good amount of rainfall due to the southwest monsoon. There was variation in rainfall within the village of $15 \mathrm{~km}^{2}$ and it ranged from $250 \mathrm{~mm}$ to $340 \mathrm{~mm}$ in July and August months. The rain fall variation was greater in August than that in July months. These results indicate the need for adoption of proper cropping system within the watershed by taking in to consideration of rainfall variation in different farms. 
Table.1 Rainfall variability at 15 locations during peak rainy months (July and August) in kharif 2009 Kothakunta subwatershed, Wargal

\begin{tabular}{|c|l|c|c|c|c|c|}
\hline S.No & Farmer Name & Latitude & Longitude & \multicolumn{2}{|c|}{ Rainfall (mm) } & $\begin{array}{c}\text { Total rainfall } \\
(\mathbf{m m})\end{array}$ \\
\cline { 5 - 7 } & & & & July, 2009 & August,2009 & \\
\hline $\mathbf{1}$ & G.Bikshapathi & $17^{\circ} 45.374$ & $78^{\circ} 37.84$ & 59.75 & 248.00 & 307.75 \\
\hline $\mathbf{2}$ & E.Sataiah & $17^{\circ} 45.307$ & $78^{\circ} 37.999$ & 58.95 & 221.75 & 280.70 \\
\hline $\mathbf{3}$ & T.Yadagiri & $17^{\circ} 45.298$ & $78^{\circ} 37.072$ & 63.80 & 250.00 & 313.80 \\
\hline $\mathbf{4}$ & G.Usaiah & $17^{\circ} 45.444$ & $78^{\circ} 37.985$ & 61.25 & 195.55 & 256.80 \\
\hline $\mathbf{5}$ & Ch.Posaiah & $17^{\circ} 45.556$ & $78^{\circ} 37.192$ & 60.75 & 255.65 & 316.40 \\
\hline $\mathbf{6}$ & T.Chandragiri & $17^{\circ} 45.457$ & $78^{\circ} 37.429$ & 60.00 & 251.15 & 311.15 \\
\hline $\mathbf{7}$ & L.Yadaiah & $17^{\circ} 45.308$ & $78^{\circ} 37.527$ & 52.40 & 247.35 & 299.75 \\
\hline $\mathbf{8}$ & Ch.Jahimgiri & $17^{\circ} 45.56$ & $78^{\circ} 37.495$ & 56.80 & 213.15 & 269.95 \\
\hline $\mathbf{9}$ & Ch.Narsaiah & $17^{\circ} 45.828$ & $78^{\circ} 37.692$ & 64.75 & 275.00 & 339.75 \\
\hline $\mathbf{1 0}$ & E.Kishtaiah & $17^{\circ} 45.712$ & $78^{\circ} 37.783$ & 57.00 & 241.10 & 298.10 \\
\hline $\mathbf{1 1}$ & E.Ramachandran & $17^{\circ} 45.211$ & $78^{\circ} 38.001$ & 58.50 & 260.95 & 319.45 \\
\hline $\mathbf{1 2}$ & G.kanakaraju & $17^{\circ} 45.438$ & $78^{\circ} 37.834$ & 57.50 & 266.45 & 323.95 \\
\hline $\mathbf{1 3}$ & Kommusailu & $17^{\circ} 45.296$ & $78^{\circ} 37.919$ & 57.20 & 266.25 & 323.45 \\
\hline $\mathbf{1 4}$ & G.Lingam & $17^{\circ} 45.282$ & $78^{\circ} 37.857$ & 58.25 & 240.20 & 298.45 \\
\hline $\mathbf{1 5}$ & G.Yallaiah & $1^{\circ} 46.121$ & $78^{\circ} 37.694$ & 58.75 & 235.85 & 294.60 \\
\hline Range & & & & $52.4-$ & $195.55-$ & $269.95-323.95$ \\
\hline & & & & 64.75 & 266.45 & \\
\hline SD+/- & & & & 2.98 & 21.34 & 21.89 \\
\hline
\end{tabular}

Fig.1 Rainfall distribution in different months during 2008, 2009, 2010 and 2011 at Kothakunta sub watershed Wargal

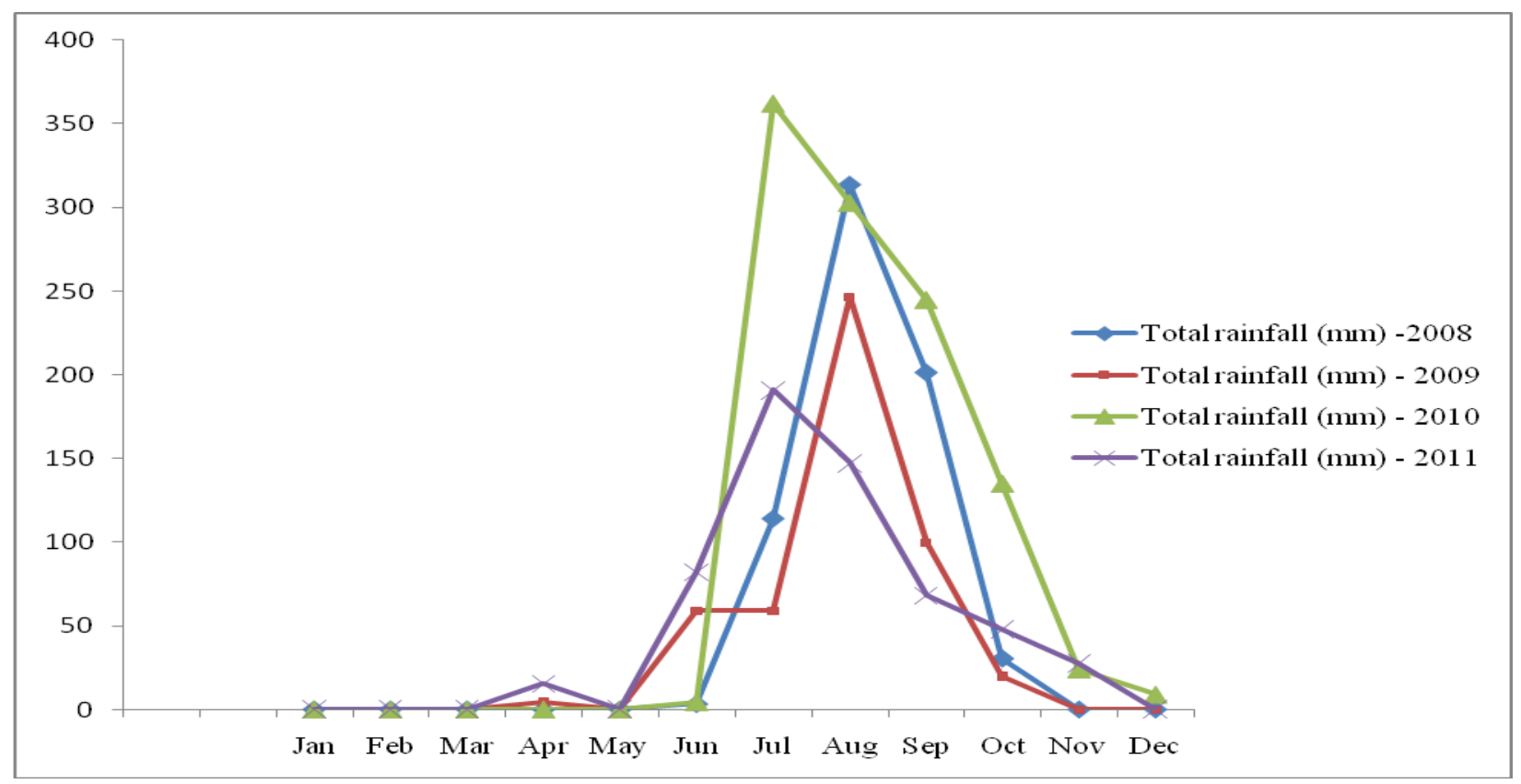


Fig.2 Rain fall variability (Range) during peak rainy months in Kothakunta Sub watershed, Wargal

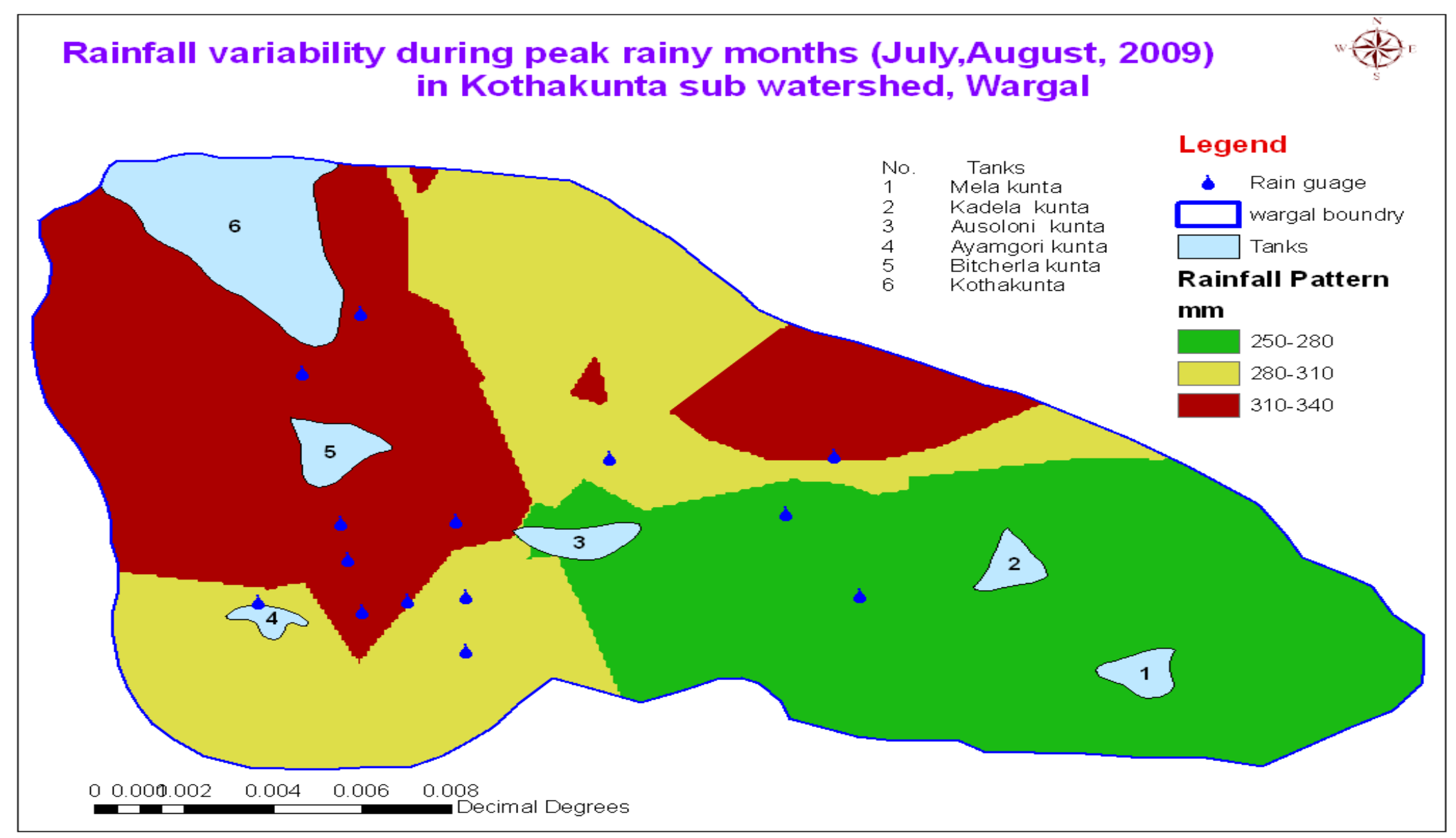




\section{References}

Field, C.B. (Ed.). 2014. Climate ChangeImpacts, Adaptation and Vulnerability: Regional Aspects; Cambridge University Press: Cambridge, UK.

Food and Agriculture Organization (FAO). 2007. Land Evaluation towards a Revised Framework; Land and Water Discussion Paper; FAO: Rome, Italy, Volume 6.

Francis Ndamani and Tsunemi Watanabe. 2015. Influences of rainfall on crop production and suggestions for adaptation. International Journal of Agricultural Sciences. 5 (1): 367-374.
Kumar, V., Jain, S. K., and Singh, Y. 2010. Analysis of long-term rainfall trends in India. Hydrol. Sci. J., 55: 484-496.

Mearns, R., and Norton, A. 2009. The Social Dimensions of Climate Change: Equity and Vulnerability in a Warming World; The World Bank: Washington, DC, USA.

Solomon, S., Qin, D., Manning, M., Averyt, K., and Marquis, M. (Eds.). 2007. Climate change -the physical science basis: Working Group I Contribution to the Fourth Assessment Report of the IPCC; Cambridge University Press: Cambridge, UK.

\section{How to cite this article:}

Uma Devi, M., M.D. Reddy, A. Mani, D. V. Mahalakshmi and Bhavani, O. 2020. Spatial and Temporal Rainfall Variability of Sub Watershed in Deccan Plateau, India. Int.J.Curr.Microbiol.App.Sci. 9(10): 1073-1078. doi: https://doi.org/10.20546/ijcmas.2020.910.128 